\title{
Prevalence of overuse (injury) syndrome in Australian music schools
}

\author{
H J H FRY \\ From 16 Howard Street, Kew 3101, Victoria, Australia
}

ABSTRACT Overuse (injury) syndrome, common in musicians, is characterised by persisting pain and tenderness in the muscles and joint ligaments of the upper limb due to excessive use and in more advanced instances by weakness and loss of response and control in the affected muscle groups. This occurs typically in tertiary music students when their practice load is raised. In seven Australian performing music schools the minimum prevalence of the condition was found to be $9.3 \%$. In two music schools where the study was more controlled the incidences were $13 \%$ and $21 \%$. The factors leading to overuse (injury) syndrome may be identified as follows: (1) the genetic factor of vulnerability which cannot be altered; (2) the student's technique which may be influenced by teaching and application so that it is more "energy efficient"; and (3) the time $x$ intensity of practice which is totally within the student's control. Prevention involves education of staff and students about the overuse process, rationalisation of practice habits and repertoire, abolition or reduction of static loading of the weight of the instruments, and earlier reporting when the problem is most easily corrected. Psychological problems arising in this syndrome appeared to occur as a reaction to the condition rather than as a causal factor.

There are two well defined music populations-the symphony orchestra and the music school. The prevalence of overuse (injury) syndrome in the symphony orchestra has been studied separately ${ }^{1}$ and showed a prevalence of painful overuse of over $50 \%$ in these orchestral musicians. The present study is concerned with previous events-that is, the occurrence of the syndrome in tertiary music students, specifically excluding consideration of other specific clinical entities such as nerve entrapments, tenosynovitis, arthritis, trauma, and others. The overuse (injury) syndrome has been defined as those changes brought about in the muscles and joint ligaments from excessive use, causing pain, loss of function, and almost always demonstrable tenderness in the affected structures. $^{2-6}$ Overuse in musicians affects mostly the upper limb but also in wind players the muscles of the lips and cheeks, the soft palate, and the throat. The spinal pain derived not only from muscular overuse but from other pain sensitive structures whose direct examination is precluded.

Overuse was reasonably well understood a century ago. Poore in 1887 described muscular overuse in pianists and contrasted it with the same condition in writers which was more common. ${ }^{7}$ He concluded that

Accepted 13 May 1986
"This is due I believe to the fact that the muscles, the derangement of which causes breakdown in piano playing are larger, more numerous and in more common requisition for general purposes than are the muscles (most commonly the interossei) whose breakdown causes writer's cramp." Like contemporary writers $^{389}$ he was aware that complete rest of the structures was the only cure. He stated inter alia that, "The most important point in treatment is rest. The excessive use of the hand must be discontinued and it is often necessary to insist on this rather forcibly." Nowhere in his writing did Poore suggest that this condition might be related to conversion hysteria, tenosynovitis, or have an inflammatory basis.

Interest in the condition in musicians appeared to lapse until 1983 when Hochberg et al described it as "tenosynovitis," also describing loss of muscle function. ${ }^{10}$ The Lancet among other matters contrasted the modest medical care of the musician with the elaborate care of the sportsman. ${ }^{8}$

In July and August 1985 five large international conferences considered these matters at length all within a space of two months (Mind, Body and the Performing Arts Conference, New York University, 15-19 July 1985; Medical Problems of Musicians, 3rd annual symposium, Aspen, Colorado, 25-28 July 1985; International Society for the Study of Tension 
in Performance (ISSTIP), Princeton, 28 July-2 August 1985; 4th International Symposium of Music Education in the Handicapped, New York, 5-9 August 1985; and 1985 International Conference of Symphony and Opera Musicians (ICSOM) session on "occupational maladies of musicians," San Francisco, 17 August, 1985).

The outlook of the tertiary music student therefore who is aiming at a career giving performances must be critically examined. It is more logical to confront the problem, for preventive measures, the ultimate aim of such a study, are then more likely to result. Most students wishing to pursue a career in music will do so by studying at one of the tertiary music schools. It is possible to combine even a full music degree or course with another degree such as law or arts. Music units may be a major part of an arts degree in several universities. Music students seeking performance qualifications must study at a "performing" faculty and would practise usually between three and six hours a day. Some students may practise well in excess of these times and the dedication of some of them is astonishing. Much of the practice is highly repetitious, difficult passages being practised over and over again to gain accuracy, endurance, motor memory, and ease of execution. It is the result of such practice with which this investigation is mostly concerned.

As this study is totally Australian, the statement of the musical activity of the country itself is the logical starting point. The population of Australia is nearly 16 million. There are eight full time professional symphony orchestras and eight part time professional symphony orchestras. Of the 13 tertiary music schools, 11 are performing faculties. There are 13800 members of the Musicians Union, and 80000 Australian Music Examinations Board (AMEB) examinations were taken in 1984 (about 55000 performance and 25000 theory).

\section{Materials and methods}

I interviewed and examined the students and staff from seven of Australia's 11 performing music schools. Affected students were for the most part in terviewed and examined individually and in private? in all institutions but one they were encouraged to attend. It was accepted that the result was likely to be short of the total prevalence because:

(1) Problems could emerge later in the year after the survey had been completed and

(2) Some students with problems did not wish to be "uncovered" or they may have been afraid of losing the goodwill of their teacher.

In the two music schools where I conducted regular clinics throughout the year the figures were probably $\vec{\omega}$ closer to the true prevalence. The students with overo use (injury) syndrome were analysed in tables and the clinical findings recorded. The criteria of severity of the overuse process is given in the appendix.

\section{Results}

\section{EPIDEMIOLOGICAL FINDINGS}

The figures for the music schools were all combined tom give the totals in the tables.

All five sections of music making are affected by运 overuse (injury) (table 1). The woodwinds are the worst affected $(13 \%)$ whereas the brass is leasto affected $(7 \%)$. There is a greater female enrolment. except for brass and percussion but all sections showed disproportionately more female casualties than male. The gross prevalence of overuse (injury) syndrome is $\mathbf{9} \cdot \mathbf{3 \%}$.

Over half the affected students had painful hands $\frac{\mathbb{Q}}{\square}$ and wrists. The pain originated from the affected in $\overrightarrow{0}$ trinsic muscles of the hand and some joint ligaments,, notably those of the carpometacarpal joint of the? thumb, the radial side of the wrist, and sometimeso colateral ligaments of the metacarpophalangeal and proximal interphalangeal joints. Other muscle groups more proximally showed demonstrable tenderness in about one third of the students, and nearly a quarter. of the music students had spinal pain at at least one? level (table 2). The complexity of spinal pain involves 3 a component at least of muscular tenderness, mosto commonly seen in the longitudinal muscles of the cer-

Table 1 Total student population

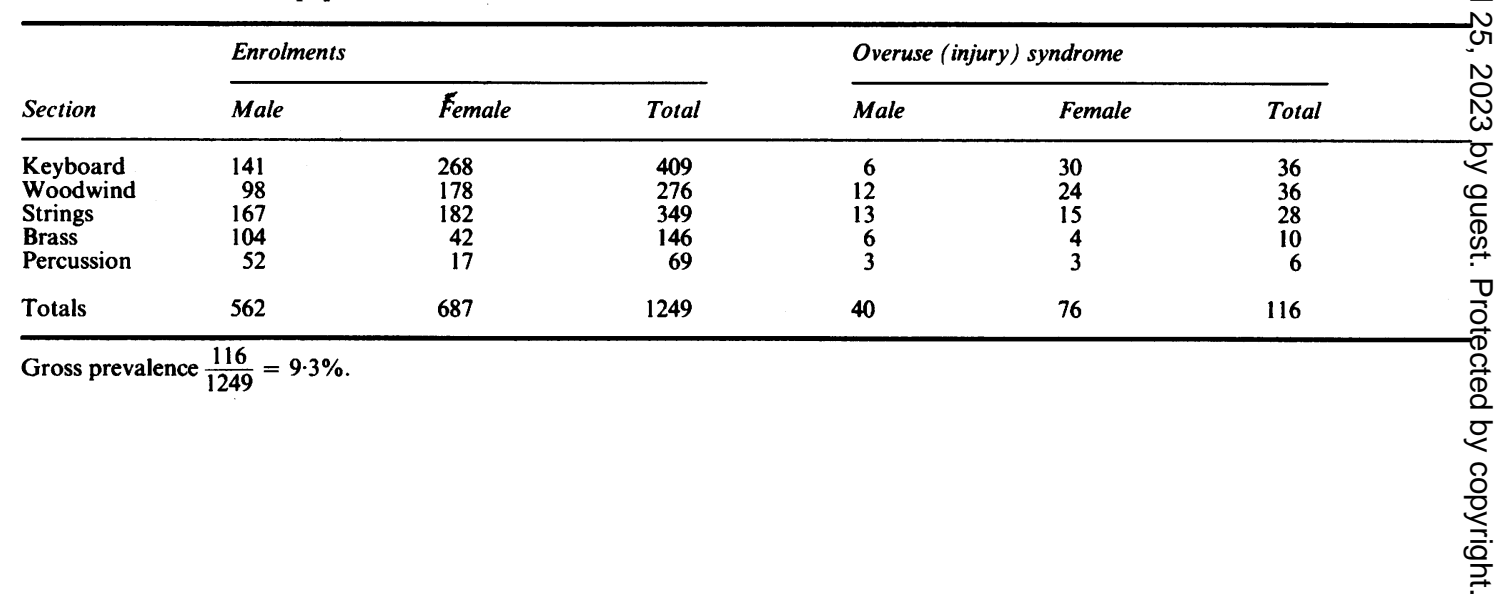


Table 2 Site of pain in 116 students with overuse (injury) syndrome

\begin{tabular}{ll}
\hline Site of pain & No of patients \\
\hline Hand and wrist & 63 \\
Arm (elsewhere) & 40 \\
Spine & 23 \\
\hline
\end{tabular}

vical and upper thoracic spine. Muscular overuse affecting lips, if present, palate, and throat was recorded separately. Nearly half these young people had had their symptoms for longer than 12 months (table 3).

The severity of the condition may be arbitrarily but usefully graded in a five interval system. Women are overrepresented in all but the grade 1 severity, and in the three most serious grades, 3-5, there are about three women affected for every man (table 4 ).

Institution $A$ had a total enrolment of 290 students and an incidence of just over $5 \%$. Interviews and physical examinations took place early in the year and it was known that other students contracted overuse (injury) syndrome later in the year, so this figure constitutes a "bedrock" or minimum prevalence. Injuries were concentrated in the grades 3 and 4 severity and there was a concentration in the one to five year period plus duration of history. This institution had good supporting student health services and the problem was taken seriously at all times.

Institution $B$ had an enrolment of 100 students with five instances of overuse (injury) syndrome. The survey examinations took place during vacation time towards the end of the year when some students were far away and since at least one other injury was known to have taken place before the end of the year, this figure must also be regarded as a bedrock or minimum prevalence figure. Four out of five of these students had a history in the two to five year period, all had painful hands and wrists, all were women, and this small number was spread among grades 1-4.

Institution $C$ had an enrolment of 192 students with 10 students affected, giving a gross prevalence figure of around $5 \%$. All but one of the affected students

Table 3 Duration of symptoms in 116 students with overuse (injury) syndrome

\begin{tabular}{lc}
\hline Duration of history & No of patients \\
\hline $0-4$ weeks & 11 \\
1-6 months & 36 \\
$7-12$ months & 19 \\
1-2 years & 25 \\
2-5 years & 18 \\
Over 5 years & 7 \\
Total & 116 \\
\hline
\end{tabular}

Table 4 Severity of overuse in 116 students with overuse (injury) syndrome

\begin{tabular}{lccc}
\hline Grade of injury & Male & Female & Total \\
\hline 1 & 15 & 10 & 25 \\
2 & 10 & 22 & 32 \\
3 & 7 & 21 & 28 \\
4 & 6 & 17 & 23 \\
5 & 2 & 6 & 8 \\
Totals & 40 & 76 & 116 \\
\hline
\end{tabular}

were women and all had either grade 3 or grade 4 injuries. None had a history longer than two years, all had painful hands and wrists. Little is known about the possibility of there being other affected students at the time this institution was visited, but as this was only halfway through the year and the performance examinations were far off, the probability that further injuries occurred is high, and so this figure must also be regarded as a bedrock or minimum prevalence figure.

Institution $D$ had an enrolment of 175 students with 11 students affected, giving a gross prevalence of $6 \%$. Little was known about the possibility of there being other affected students when the interviews and examinations were carried out. Since they were carried out in the middle of the year before the pressure of exams was felt, further overuse probably occurred, so that this figure of $6 \%$ must also be regarded as bedrock or minimum prevalence. In this institution all but one of the affected students were women, they were spread through grades 2 to 5 severity, there being no grade 1 affections. There was a spread from short to long duration of history, five of them having histories longer than 12 months. All affected students had painful hands and wrists.

Institution $E$ had an enrolment of 147 students with 19 affected, giving rise to a gross prevalence of $13 \%$. All but two students were women, there was a peak in the grade 3 severity and a peak in the duration of history up to six months. This was directly attributable to those students sitting performance exams in November, then going to music camp in February (see later). Fourteen students had painful hands and wrists. In this institution the level of interest was so high in the problems of overuse that there was no reason to conclude that this was a bedrock or minimum prevalence.

Institution $F$ had an enrolment of 197 students with 25 students affected, giving a gross prevalence of $13 \%$. I held clinics at this college where the students were encouraged to report early symptoms. Men and women were affected about equally, 20 had early injuries ( 10 grade 1 and 10 grade 2), in the duration of history the concentration showed 15 students with 
less than a 12 months history and only three over two years. This institution has included in its curriculum teaching on the physical consequences of music making for some two years.

Institution $G$ had an enrolment of 147 students with 31 students affected, giving a gross prevalence of approximately $21 \%$. I also held clinics at this institution and the students were encouraged to report their symptoms early. Men and women were about equally represented, the grades of injuries seen were concentrated in grades 1 and 2 ( 23 students) and 23 students had a history of less than 12 months. Fourteen students had painful hands and wrists. This institution had also taught the nature of overuse (injury) syndrome for the previous two years.

\section{Clinical findings}

The symptoms of overuse injury being referred to are described in detail elsewhere. ${ }^{4}$ Pain, with various prodromas or accompaniments was the rule and most students (according to severity) displayed some loss of technique. This was shown by weakness, loss of response (diminished agility and speed), or loss of control (diminished accuracy).

Some degree of depression appeared evident in all those students with grade 3 severity or above and in those treated by a total avoidance of pain inducing activities programme a variable transient increase was usually noticed in the first three weeks.

There was virtually a $100 \%$ correlation between the onset of symptoms and an increase in the time multiplied by intensity of music practice. This was usually brought about by preparations for examination, a recital, a competition, study of a new work, a set of exercises, or a change of teacher. In the lower grades of severity pain may be produced by one work or one exercise only, all other repertoire being unaffected. Failure to desist at this stage caused many students to progress to a higher grade of involvement. Clarinettists' overuse typically affects firstly and most profoundly the first web space muscles of the right hand and the ligaments at the base of the thumb and radial side of the wrist, the former in sustained muscular contraction the latter suffering sustained loading from the weight of the clarinet borne on the right thumb. The students did not show the pain in the neck and left shoulder attributable to holding up the violin as seen in the orchestral players so commonly ${ }^{1}$ but often showed pain in the shoulders and rotator cuff tenderness with a static loading of the arm itself. In established, more chronic examples onset of pain in the affected muscles may postdate the causal activity by up to 12 hours. ${ }^{4}$ The music student did not always have the benefit therefore of nature's warning signal.
An attitude of cynicism and accusations of hysteri务 and misbehaviour appeared to have a serious effec? on students with overuse (injury) syndrome. The thought of losing the goodwill of the teacher and the faculty, with all that that implies, is highly in? timidating to the student who will then continue to practise into a worse grade of severity, presenting later with more serious problems. This was clearlye seen in one of the institutions. Recovery by rest was often curtailed by institutional and personal pressures. Students, for the most part, tended to conceaL their condition for as long as possible so that playing could be continued. The physical signs seen in the students with grade 3 severity or above persisted for many months even when put on a total rest pro? gramme. Those with minimal physical signs whot could be treated while allowing them to continue their music making often lost these physical signs in as little as three to four weeks.

All students showed some psychological disturbances, obvious enough to be recognised by क्के surgeon. Anxiety predominated. They expressed theie concern about their future, about the possibility of not being able to continue studying music, and ex-pressed considerable anxiety about getting better. The anxiety was usually shared by the student's family. $A^{N}$ depression would seem to be distinct from this ${ }^{34}$ and was usually acknowledged both by the family, when they could be interviewed, and by the student.

Over half the students had been told either by कै doctor or by friends, and even parents, that there was nothing really wrong with them and that it was "in the mind." These students expressed a much higher grade of anxiety and expressed a loss of self esteem Those students showing deterioration of their tech nique expressed more anxiety about this than about the pain on playing. About a quarter of these students had been told at some stage that their problem was due to "technical faults" so they practised all the harder and worsened their condition. The dilemmas faced by these students a short time before a per $\frac{0}{3}$ formance or an exam is extremely stressful. If they continue to practise they may obtain some sort of pass but they may also worsen their condition. If they undergo a prolonged and radical rest programme they do not sit the examination and they fear that they could be out of the mainstream of music. ${ }^{1112}$

\section{Discussion}

The term "overuse" reflects what appears to happerfe when tissues are taken beyond their biological toler ance. The term "injury" is more controversial. This term is certainly applicable to the muscle damage found by Howard ${ }^{13}$ and Thompson et al ${ }^{14}$ in thei patients with hand use intensive work whose muscles? 
were biopsied. It is also applicable to the marathon runners where muscle fibre necrosis has been shown at biopsy, these changes not being present in runners of shorter distances. ${ }^{15}$ It is also applicable to overuse of overperforming muscles in old victims of poliomyelitis and proved by biopsy. ${ }^{16}$ "Iron pumpers" may get a similar painful overuse from excessive body building exercises which may take many months to resolve. Though this syndrome is well known to sports medicine practitioners, there are no published studies and no biopsy evidence. In musicians' overuse the muscles and joint ligaments remain persistently tender and show loss of function. On this basis a case may be made for describing the syndrome with the word injury enclosed in parentheses. If muscle biopsy studies show a structural change to match clinical signs the parentheses could be removed. It is difficult to know into what other class of disorder the overuse syndrome would fit.

Acute muscle tears caused by the contractile actions of the muscle themselves (and not always gravity assisted) are exceedingly common and Lederman has termed this "acute overuse." 17 The devotees of conversion hysteria and its various euphemisms claim that muscle is unable to injure itself by its own contractions. ${ }^{18}$ It is also claimed that tenderness in a structure (demonstration of which has so much clinical importance for the surgeon) is a symptom and not a sign. It is doubtful whether this represents a mainstream medical viewpoint, for where is the difference in showing localised tenderness in the muscle from tenderness in the right iliac fossa (appendicitis), rebound tenderness (peritonitis), or a painful swollen joint as opposed to a painless swollen joint? A tooth that is tender to percussion (as opposed to one which is not) is a vital sign for the dentist in toothache. A glomus tumour is virtually diagnosed by its tenderness. The sports medicine practitioner probably has more expertise in assessing muscular and ligamentous tenderness than any other specialty. Although a subjective element is present in tenderness, it may be shown convincingly with reasonable clinical skills.

The depression found in overuse (injury) syndrome needs further investigation. Its association with this condition is inescapable. It is common observation that mood elevation follows physical exercise in the morning, particularly "jogging." A relation between mood and muscular activity has been described ${ }^{19}$ and it would not be too fanciful to postulate a derangement of this mechanism to explain what happens in overuse (injury) syndrome.

Implication of bad teaching and allegations of "misuse" on the part of the students do not furnish an adequate explanation for the findings here and such statements may have unfortunate consequences. The teachers may become defensive and the students may increase the tendency already present for them to conceal their problems. Unless this can be translated into some sort of positive and helpful action, such statements are stressful to the affected students as they are totally pejorative and offer no constructive help. Rather should it be realised that the muscles represent stored energy like a car battery and that high utilisation with inadequate opportunity for restitution may reach a point where normal restitution cannot occur.

The three major factors leading to overuse are:

(1) The genetic factor which cannot be changed. This study shows that some students were clearly more vulnerable to overuse (injury) syndrome than others. Possibly the best example is the group of AMEB grade 6 level clarinettists of comparable standards who quadruple their practice time (and therefore $\mathbf{8 0 0}$ gram + loading on the right thumb) at music camp and report in, unable to play because of painful thumbs. They present in a particular order that must reflect a genetic factor.

(2) The student's technique is often overdrawn as being the only factor that matters. The music teacher strives to teach the student a tension free, effortless technique where wasteful uncontrolled excessive muscular effort is avoided. The more successful students will be that much further away from the threshold of overuse.

(3) Intensity $\times$ time of practice is a totally controllable factor and seems to be the most important of the three factors. This is exemplified by the correlation of an increase in this factor with the onset of overuse (injury) syndrome in this series.

Prevention of overuse syndrome in the music school must depend on education in the music schools along the following lines.

(1) Education of the students and staff of music institutions on the nature of overuse (injury) syndrome so the students will gain sufficient basic information for self preservation and the staff are able to advise the student what options are available for them, whether it is possible for them to remain in the mainstream of music, and whether their aspirations for a performing career are realistic. ${ }^{12}$

(2) Safe and sensible practice habits that are disciplined rather than dedicated must be encouraged. Segments of say 25 minutes followed by a five minute break will allow the muscles and joint ligaments to rest and the muscles will in fact be more responsive after a five minute break. If the breaks are not taken the law of diminishing returns ensures reduced response as the muscles become progressively more fatigued and more drained. Since the threshold of overuse (injury) syndrome in any individual is unknown until it occurs, staying within the safe limits 
should be the aim. Excessively long practice hours also isolates the student from the rest of the community for unnaturally long periods. Ten to twelve hours practice a day among students is not unknown and the physical and social risks are counterproductive to the educational process.

(3) Muscular activity used to hold up heavy instruments or suspending woodwind instruments from the right thumb competes directly with the skilled muscle activity of music making and this should be abolished where possible. Although post support for a clarinet or oboe, floor support for a bassoon, and external supports for the heavy French horn and the awkward violin and viola may at first upset the music teacher, one would hope the increased freedom of technique, as well as the greater safety from overuse, would be an irresistible attraction.

Psychological disturbances observed in these students appear to arise secondarily and as a reaction to the condition. A worse degree of anxiety with loss of self esteem was seen in most students who were told that their problems were of psychological origin or where their faculty members adopted a cynical viewpoint. Of those students who recovered on a rest programme and resumed their course, the psychological symptoms largely disappeared, so this study does not support the proposition of a primary psychological condition.

\section{Appendix}

\section{GRADING OF SEVERITY OF OVERUSE (INJURY) SYNDROME}

Grade 1 -Pain in one site on playing. This must be regular rather than occasional, and pain ceases when the musician stops playing.

Grade 2-Pain in multiple sites on playing. Perhaps minimal loss of coordination. Physical signs of tissue tenderness are minimal. No interference with other uses of the hand.

Grade 3-Pain persists away from the instrument, early involvement in other uses of the hand which now cause pain. Early loss of muscle function, weakness, loss of response (loss of agility, speed), loss of control (loss of accuracy, clumsiness). Physical signs from tender structures.

Grade 4-All common uses of the hand cause pain, but these uses are possible as the pain is tolerated? Usually loss of muscle function weakness, loss of re: sponse, loss of control. Pronounced physical signs fof tender muscles and ligaments.

Grade 5-As for grade 4 but with loss of capacity t use the hand because of severity of disabling pain an loss of muscle function.

\section{References}

1 Fry $\mathrm{HJH}$. Incidence of overuse syndrome in the symphon $\vec{\omega}$ orchestra. Medical Problems of Performing Artis? 1986;1:51-5.

2 Fry $\mathrm{HJH}$. Physical signs in the hand and wrist in the overuse (injury) syndrome. Aust NZ J Surg 1986;56:47-9.

3 Fry HJH. Overuse syndrome in the upper limb in musicians. Med $J$ Aust 1986;144:182-5.

4 Fry HJH. Overuse syndrome-alias tenosynovitis-tendinitis $\omega$ the terminological hoax. (Special topic.) Plast Reconstr Surg 1986;78:414-7.

5 Owen E. RSI (overuse injury syndrome) in musicians. Journal of Occupational Health and Safety Australia and New Zealan\& 1985;1:135-9.

6 Fry HJH. Occupational maladies of musicians: their cause anछ prevention. International Journal of Music Education 1984;4:59-65.

7 Poore GV. Clinical lecture on certain conditions of hand and arris which interfere with performance of professional acts, especially piano playing. $\mathrm{Br} \mathrm{Med} J 1887 ; \mathrm{i}: 441-4$.

8 Anonymous. The music clinic. Lancet 1985;i:1309-10.

9 McDermott F. Repetition strain injury: a review of current un derstanding. Med J Aust 1986;144:196-200.

10 Hochberg FH, Leffert RD, Heller BD, Merriman L. Hand difficulties among musicians. JAMA 1983;249:1869-72.

11 Fry HJH. Overuse injury at music school-the dilemma. Thळ American Music Teacher 1986;36:45.

12 Fry HJH. "Overuse injury in the music school. Music Educator Journal 1986;72:46-9.

13 Howard NJ. Peritendinitis crepitans. $J$ Bone Joint Sur 1937;19:447-59.

14 Thompson AR, Plewes LW, Shaw EG. Peritendinitis crepitans and simple tenosynovitis: a clinical study of 544 cases in induse try. Br J Ind Med 1951;8:150-60.

15 Hikida RS, Staron RS, Hagerman FC, et al. Muscle fibre necrosiक associated with human marathon runners. $J$ Neuros $\$$. 1983;59:185-203.

16 Dalakas MC, Sever JL, Fletcher M, et al. Muscular symptoms if patients with old poliomyelitis: clinical, virological and immu nological studies. In: Halstead LS, Weichers DO, eds. Lat? effects of poliomyelitis. Miami: Symposia Foundation 1985:73-89.

17 Lederman RJ, Calabrese LH. Overuse syndromes in musicians Medical Problems of Performing Artists 1986;1:7-11.

18 Awerbuch M. Overuse injury -another medical view. Law News 1986;21:31-3.

19 Martinsen WE, Medhus A, Sandvik L. The effects of aerobif exercises on depression: a controlled study. $\mathrm{Br} \mathrm{Med} \boldsymbol{\omega}$ 1985;291:109. 